\title{
E. coli CD-expressing Genetically Modified Neural Stem Cells
}

National Cancer Institute

\section{Source}

National Cancer Institute. E. coli CD-expressing Genetically Modified Neural Stem Cells. NCI Thesaurus. Code C92585.

Genetically-modified neural stem cells (NSCs) transfected with the Escherichia coli (E. coli) suicidal gene cytosine deaminase (CD), with potential antineoplastic adjuvant activity. Upon intracerebral injection, E. coli CD-expressing genetically modified NSCs express the E. coli cytosine deaminase, an enzyme that catalyzes the intracellular conversion of the nontoxic prodrug 5-fluorocytosine (5-FC) into the cytotoxic 5-fluorouracil (5-FU). Coadministration of this agent with 5-FC and upon local activation of 5-FU in the brain tumor, 5-FU disrupts DNA synthesis in tumor cells thereby impeding cellular proliferation with minimal systemic exposure and toxicity. 